RESEARCH REPORT

\title{
Linking perceptions of neighbourhood to health in Hamilton, Canada
}

\author{
K Wilson, S Elliott, M Law, J Eyles, M Jerrett, S Keller-Olaman
}

J Epidemiol Community Health 2004;58:192-198. doi: 10.1136/jech.2003.014308

See end of article for authors' affiliations ....................

Correspondence to: Professor K Wilson, University of Toronto, Department of Geography University of Toronto at Mississauga, 3359 Mississauga Road N, Mississauga, Ontario, Canada L5L 1C6; kathi.wilson@utoronto.ca

Accepted 11 November 2003
Study objective: To investigate the association between perceptions of neighbourhood physical and social characteristics and three health outcomes (self assessed health status, chronic conditions, and emotional distress).

Design: Cross sectional survey data analysed in small neighbourhoods.

Setting: Hamilton, Ontario, Canada, a medium sized industrial city, located at the western end of Lake Ontario (population at the time of the study about 380 000).

Participants: Random sample of 1504 adults aged 18 years and older residing in four contrasting neighbourhoods.

Main results: Significant differences across the four neighbourhoods are apparent in self assessed health status and emotional distress, but not in chronic conditions. Neighbourhoods with lower SES reported poorer health and more emotional distress. Perceptions of the physical environment dominated social concerns in all neighbourhoods. For all three health outcomes, individual risk factors followed expectations, with measures of poverty, age, and lifestyle all significantly associated with poor health outcomes. Physical environmental problems were positively and significantly associated with poor physical and emotional health. Specifically, people reporting they dislike aspects of their neighbourhood's physical environment are 1.5 times more likely to report chronic health conditions (OR 1.56, 95\% Cl 1.19 to 2.05), while those reporting physical likes with their neighbourhood are less likely to report fair/poor health (OR $0.50,95 \% \mathrm{Cl} 0.28$ to 0.90 ) or emotional distress (OR $0.45,95 \% \mathrm{Cl} 0.26$ to 0.80 ).

Conclusions: These results demonstrate the importance of neighbourhood perceptions as a determinant of health, as well as conventional factors such as low income, lifestyle, and age. The dominance of physical environmental concerns may have arisen from the industrial nature of Hamilton, but this result merits further investigation.
$\mathrm{R}$ esearchers and policymakers now recognise the prominent part neighbourhoods play in shaping individual and population health. This recognition includes individual perceptions of neighbourhood characteristics. Policy interests in local level health planning have begun to place neighbourhood at the core for "setting policies aimed at reducing health inequalities". ${ }^{1}$ This paper reports the results of a Canadian study that addresses the following research questions: Firstly, does an association exist between perceptions of neighbourhood physical and social characteristics and three health outcomes (self assessed health status, chronic conditions, and emotional distress)? Secondly, do perceptions of physical or social characteristics exert comparatively more influence on the three health outcomes?

Current research on neighbourhoods and health addresses two main concerns. The first, relying on a quantitative ecological approach, measures neighbourhood effects of deprivation or socioeconomic status (SES). The second seeks to identify the association between perceptions of neighbourhood physical or social characteristics and health.

With the quantitative approach, neighbourhood variables often derive from individual or a composite of socioeconomic data such as, median income, unemployment, overcrowding, or car ownership. The Carstair Index of deprivation may be the best known composite measure, but several standard indices are available for use. ${ }^{2-4}$ Such neighbourhood variables have been significantly associated with mortality and morbidity even after controlling for individual socioeconomic status and other potential confounders. ${ }^{5}$ For example, using data from the US national longitudinal mortality study, Anderson $e^{t} \mathrm{al}^{7}$ found that after controlling for family income, persons residing in deprived areas (as measured by census tract median family income levels) had higher mortality rates than those in less deprived areas. Links have also been established between residing in economically deprived areas and increased prevalence of coronary heart disease or increased risk of poor self assessed health status. ${ }^{8-10}$ More generally, Pickett and Pearl ${ }^{11}$ reviewed 25 studies using multilevel data to test associations between contextual effects and health outcomes. In 23 of these studies, researchers reported significant associations between variables representing the contextual social environment and health outcomes or behaviours.

This body of research highlights the role of neighbourhood economic differences in shaping health inequalities. Most of this work, however, measures SES using large scale secondary datasets. This approach often ignores the more qualitative aspects of neighbourhood and health (environmental quality, a lack of social cohesion and commercial, health and leisure facilities, for example).

Capturing the essence of the second approach, Haan et al ${ }^{12}$ suggest that the "physical environments" in which people live and their perceptions of those environments are important determinants of health above and beyond socioeconomic influences. Others have also emphasised that policies aimed at reducing health inequalities need to focus on the place based characteristics of where people live rather

Abbreviations: SES, socioeconomic status; LISA, local indicators of spatial associations 
Table 1 Characteristics of survey neighbourhoods in Hamilton, Ontario

\begin{tabular}{|c|c|}
\hline $\begin{array}{l}\text { Neighbourhood (1996 } \\
\text { census population) }\end{array}$ & Characteristics \\
\hline $\begin{array}{l}\text { Downtown Core (24523) } \\
\text { Low income } \\
\text { High diversity } \\
\text { Northeast Industrial } \\
\text { (12135) } \\
\text { Low income } \\
\text { Low diversity }\end{array}$ & $\begin{array}{l}\text { High proportion of recent immigrants and a non-English or French speaking } \\
\text { population, high levels of mobility, low levels of education and income, high } \\
\text { unemployment, and a high proportion of visible minorities } \\
\text { Lies adjacent to the city's industrial area, contains a low recent immigrant population, } \\
\text { low levels of education and income, fairly high unemployment, and a small visible } \\
\text { minority population }\end{array}$ \\
\hline $\begin{array}{l}\text { Chedoke-Kirkendall } \\
\text { (10405) } \\
\text { High income } \\
\text { High diversity }\end{array}$ & $\begin{array}{l}\text { Moderately high proportion of recent immigrants, a mainly English or French } \\
\text { speaking population, high levels of education and income, low unemployment, a } \\
\text { moderate visible minority population presence, and high income inequality }\end{array}$ \\
\hline $\begin{array}{l}\text { Southwest Mountain } \\
\text { (15917) } \\
\text { High income } \\
\text { Low diversity }\end{array}$ & $\begin{array}{l}\text { Located within a rapidly expanding suburban location, fewer recent immigrants, high } \\
\text { education and income levels, low unemployment, and a large visible minority } \\
\text { population most of whom are able to speak either English or French }\end{array}$ \\
\hline
\end{tabular}

than concentrating only on the people themselves..$^{43}$ This includes individual perceptions of neighbourhood, ${ }^{14}$ their social relations, and their access to physical amenities (or exposure to perceived disamenities). One of the earliest studies to identify neighbourhood specific characteristics that affect wellbeing was Russ-Eft's $\mathrm{s}^{15}$ research on neighbourhood and quality of life in San Francisco, USA. Russ-Eft identified five broad neighbourhood factors that shape quality of life: environmental and physical conditions; economic conditions; facilities and services; political conditions; and personal characteristics/interpersonal relationships. Research conducted within the past few years has explored the impacts of similar neighbourhood factors on health status. This body of research has also examined associations between individual perceptions of social and physical neighbourhood environments and indicators of health status. ${ }^{16}$

For example, in their studies of health in socially contrasting neighbourhoods in Glasgow, Ellaway et al ${ }^{17}$ show that self assessed health status is associated with perceived neighbourhood problems and cohesion, while measures of emotional distress (that is, GHQ-12 scores) are associated with perceptions of individual standards of living in relation to others living in the same neighbourhood. Balfour and Kaplan $^{16}$ identify significant independent effects of perceived excessive noise, heavy traffic, inadequate lighting, and limited access to public transportation on increased risk of physical impairment for older adults in Alameda County, USA. Steptoe and Feldman ${ }^{18}$ also show significant relations between neighbourhood problems (traffic density, pollution, dirt, noise, absence of amenities, threats to self and property) and impaired physical function, self rated health, and psychological distress (as measured by the GHQ). Deteriorated neighbourhood environments have also been linked to increased stress and depression. ${ }^{19-21}$

In this paper we seek to extend current knowledge on the links between neighbourhood and health by incorporating both positive and negative perceptions of neighbourhood characteristics and by examining the extent to which perceptions of physical and social characteristics influence, differentially, health outcomes. The study is situated in the industrial city of Hamilton, Ontario, Canada, located on the western tip of Lake Ontario, about $60 \mathrm{~km}$ west of Toronto (population at the time of the study about 380 000). Our findings contribute to knowledge on the relative contributions of perceived social and physical characteristics of neighbourhoods to individual health and contribute potentially to research on the relations between these types of characteristics. $^{22} 23$

Table 2 (A) Classifying perceptions of neighbourhood reported by survey respondents

\begin{tabular}{|c|c|c|}
\hline Perceptions of neighbourhood & Categories & Typical responses \\
\hline \multirow[t]{2}{*}{ Neighbourhood likes } & Social & $\begin{array}{l}\text { "People in the neighbourhood look out for each } \\
\text { other." } \\
\text { "It's small and you know people." }\end{array}$ \\
\hline & Physical & $\begin{array}{l}\text { "It's got trees...it's actually green." } \\
\text { "I like the amenities and transportation is so } \\
\text { convenient." }\end{array}$ \\
\hline \multirow[t]{2}{*}{ Neighbourhood dislikes } & Social & $\begin{array}{l}\text { "Places in my areas are rented and some of the } \\
\text { landlords do not check to see who they are } \\
\text { renting to and this makes the neighbourhood } \\
\text { somewhat unsafe." } \\
\text { "It's not safe to go out alone after dark." }\end{array}$ \\
\hline & Physical & $\begin{array}{l}\text { "My street has become very noisy." } \\
\text { "Pollution from the steel company." }\end{array}$ \\
\hline \multirow[t]{3}{*}{ Neighbourhood improvements } & Social & $\begin{array}{l}\text { "Get rid of prostitutes and drug people." } \\
\text { "Probably if we had more community sponsored } \\
\text { activities, fitness, crafts." }\end{array}$ \\
\hline & Physical & "Less traffic and noise." \\
\hline & & $\begin{array}{l}\text { "Cut down on the amount of transport such as } \\
\text { trucks that come into the neighbourhood... maybe } \\
\text { industrial is what I'm getting at then to improve } \\
\text { the air quality." }\end{array}$ \\
\hline
\end{tabular}


Table 2 (B) Neighbourhood perceptions (selected examples)

\begin{tabular}{ll}
\hline $\begin{array}{l}\text { Social neighbourhood } \\
\text { characteristics }\end{array}$ & $\begin{array}{l}\text { Physical neighbourhood } \\
\text { characteristics }\end{array}$ \\
\hline Prostitution & Noise \\
Homelessness & Pollution \\
Crime & Green space \\
Safety & Traffic \\
Friendly neighbours & Maintenance of homes/buildings \\
Amenities (schools, day care, & Parking \\
recreation centres) & \\
\hline
\end{tabular}

\section{METHODS}

Data for this study came from a cross sectional health survey, designed to assess determinants of health at the local level, conducted in four neighbourhoods in Hamilton, Ontario. A detailed description of the neighbourhood selection process can be found in Luginaah et al. ${ }^{24}$ In summary, neighbourhoods were selected through a combination of statistical methods that used socioeconomic and demographic data extracted at the census tract level from the 1996 census of Canada in conjunction with smoking data from a random survey of adults. Principal component analysis, local indicators of spatial association (LISA), and geographical information systems were used to identify neighbourhoods representing clusters of 17 socioeconomic and demographic determinants of health and related risk factors. This analysis was coupled with qualitative interviews with prominent local decision makers and key informants, which identified similar areas of interest for study. The goal was to select neighbourhoods with a range of characteristics representing salient hypotheses from the population health literature. Interestingly, the selected neighbourhoods displayed various combinations of economic wealth and social diversity, including high versus low income and high versus low social and demographic diversity (for example, lack or presence of recent immigrants, visible minorities, etc). The neighbourhoods selected (see figure 1) are referred to as ChedokeKirkendall (high income and high diversity), the Downtown Core (low income and high diversity), Northeast Industrial (low income and low diversity), and the Southwest
Mountain (high income and low diversity) (see table 1 for specific neighbourhood characteristics).

A telephone survey $(\mathrm{n}=1504)$ was administered to a random sample of about 300 selected people in each neighbourhood and to an additional 300 respondents randomly chosen from across the city (called the "Old City" in figure 1 because of a subsequent boundary change that occurred after our study began) excluding the four neighbourhoods between November 2001 and April 2002. The survey was completed by people aged 18 years and older and has an overall response rate of $60 \%$. The survey contained a range of questions designed to capture residents' perceptions of their neighbourhoods, social and community networks, health status and behaviours, use of healthcare services, and demographic and socioeconomic characteristics. Approval for this research was granted by the university ethics committee.

Logistic regression analysis was used to examine the relation between three health outcomes, including: self assessed health status (fair/poor versus good/very good/ excellent), chronic conditions (one or more), emotional health (using the GHQ-20), ${ }^{25}$ and perceptions of neighbourhood environments. A backward conditional regression model with a $\mathrm{p} \leqslant 0.1$ (to be inclusive) was conducted for each health outcome and included a range of individual factors. The use of stepwise regression for neighbourhood analysis has been validated by other studies. ${ }^{27}{ }^{28}$ Independent variables included in all initial backward conditional regression models represented a range of factors including length of residence, condition of dwelling, a neighbourhood of residence dummy variable (Old City is the reference category), as well as a range of demographic and socioeconomic factors.

A minority of respondents refused to report income (17\%). Subsequent analysis revealed that older women with low education and poor health status were more likely to refuse this question. To include more cases in the final analysis and overcome this systematic bias, values were interpolated using a hot-deck imputation approach ${ }^{29}$ and Stata 7 software. The hot-deck approach stratifies the sample based on gender, age, education and employment status, factors that were associated in our sample with lower reported income among those who did report. For every missing value, one case with the same characteristics for the stratification variables is chosen randomly and the associated income value of the

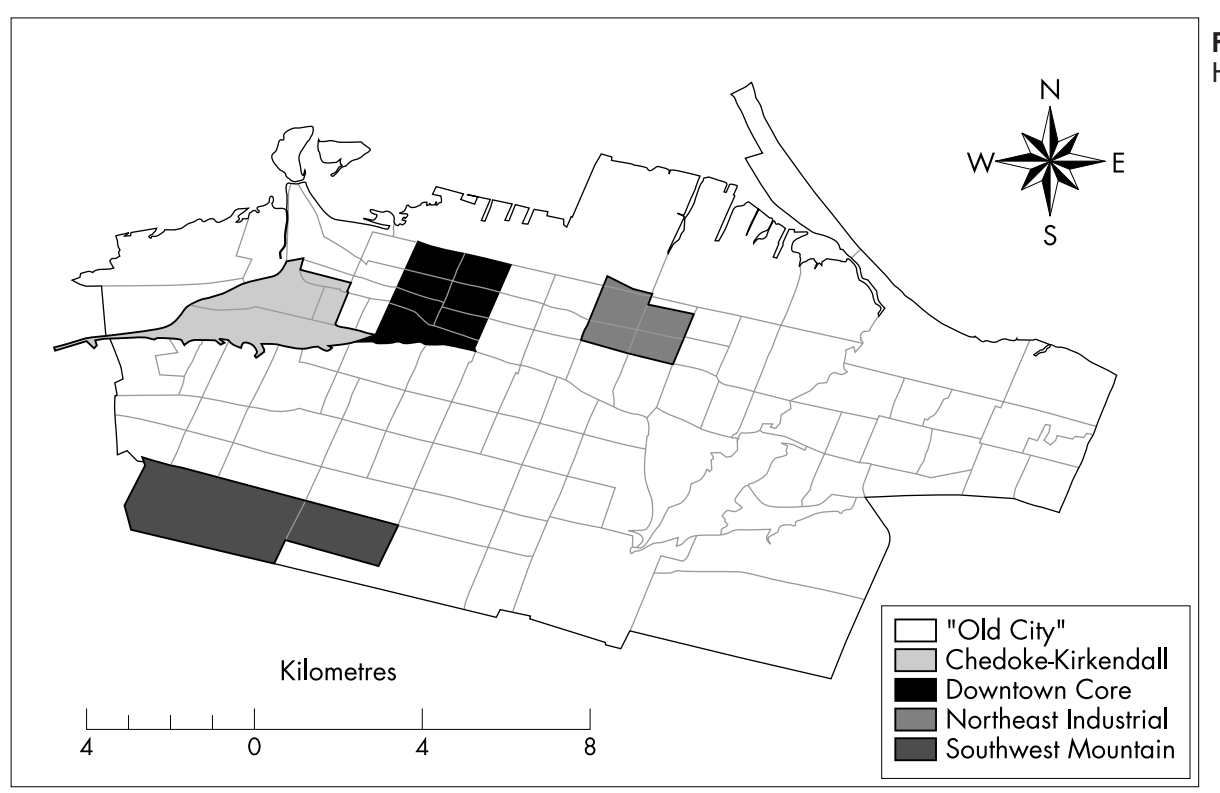

Figure 1 Study neighbourhoods in Hamilton, Ontario Canada. 
Table 3 Health status and neighbourhood perceptions across neighbourhoods of residence

\begin{tabular}{|c|c|c|c|c|c|c|}
\hline \multirow[b]{2}{*}{ Variable } & \multirow[b]{2}{*}{ Category } & \multicolumn{5}{|l|}{ Neighbourhood (\%) } \\
\hline & & Chedoke-Kirkendall & Downtown Core & Northeast & Mountain & Old City \\
\hline Health status ${ }^{* \star *}$ & Fair/poor & 10 & 20 & 23 & 10 & 12 \\
\hline Chronic conditions & 1 or more & 55 & 54 & 56 & 55 & 57 \\
\hline $\mathrm{GHQ}^{* *}$ & Score 4+ & 9 & 15 & 13 & 7 & 8 \\
\hline \multirow[t]{3}{*}{ Neighbourhood dislikes ${ }^{* \star *}$} & None & 34 & 24 & 27 & 49 & 40 \\
\hline & Social & 14 & 35 & 21 & 19 & 19 \\
\hline & Physical & 52 & 42 & 52 & 32 & 42 \\
\hline \multirow{3}{*}{ Suggestions for improvement ${ }^{\star * *}$} & None & 24 & 20 & 15 & 40 & 30 \\
\hline & Social & 5 & 20 & 10 & 12 & 13 \\
\hline & Physical & 71 & 60 & 75 & 48 & 58 \\
\hline \multirow[t]{3}{*}{ Neighbourhood likes ${ }^{\star * *}$} & None & 5 & 16 & 13 & 5 & 9 \\
\hline & Social & 52 & 33 & 43 & 61 & 49 \\
\hline & Physical & 43 & 51 & 45 & 34 & 42 \\
\hline Neighbourhood satisfaction*** & Dissatisfied & 3 & 18 & 13 & 1 & 6 \\
\hline
\end{tabular}

"donor" substituted for the missing income data. The interpolated values are slightly lower than the sample mean but this is expected given the characteristics associated with non-reporting income discussed above. This method is similar to imputation used in related studies. ${ }^{16}$

In addition, individual risk factors were included in the models, including three dichotomised variables that compare smokers with non-smokers, people who have exercised in the past three months with those that have not, and overweight compared with non-overweight people, as measured by body mass index (an index of weight to height).

Those independent variables at or near conventional significance of $p \leqslant 0.05$ in each of the backward stepwise regression models were then selected and entered manually into a multiple regression model until a parsimonious model was achieved. As a result, while all variables were entered in the initial stepwise regression model, the results presented in table 4 are only for those variables included in the parsimonious model for each health outcome. Given the a priori importance attached to neighbourhood of residence, the neighbourhood variable was forced into each model.

In much of the research on neighbourhood and health, respondents are asked to rate the extent to which a list of predefined neighbourhood characteristics are problems in their neighbourhood. For example, Ellaway et al ${ }^{17}$ measure respondents' perceptions of neighbourhood by asking them to assess 13 socioenvironmental problems (for example, vandalism, nuisance from dogs, burglaries, lack of recreational facilities). Others have used similar instruments. ${ }^{16-18}$ In contrast, in the Hamilton survey respondents were allowed to respond to two open ended questions designed to measure likes and dislikes about their neighbourhood. Only the first mention was recorded. Respondents were also asked to suggest the most important thing that could be done in their neighbourhood to improve or maintain their health. Respondents could provide up to three mentions for this

Table 4 Logistic regression models for examining neighbourhood perceptions as determinants of health

\begin{tabular}{|c|c|c|c|c|c|c|c|}
\hline \multirow[b]{2}{*}{ Variable (ref) } & \multirow[b]{2}{*}{ Classification } & \multicolumn{2}{|c|}{ Self assessed health status } & \multicolumn{2}{|l|}{ GHQ } & \multicolumn{2}{|c|}{$\geqslant 1$ Chronic condition } \\
\hline & & OR & $(95 \% \mathrm{Cl})$ & OR & $(95 \% \mathrm{Cl})$ & OR & $(95 \% \mathrm{Cl})$ \\
\hline \multirow[t]{3}{*}{ Age (18-24) } & $25-44$ & & & & & $3.11^{* \star *}$ & (2.08 to 4.67 ) \\
\hline & $45-64$ & & & & & $8.27^{\star * *}$ & (5.47 to 12.52 ) \\
\hline & $65+$ & & & & & $9.91^{* * *}$ & (5.95 to 16.51 ) \\
\hline Sex (male) & Female & & & $1.70^{* *}$ & (1.17 to 2.46$)$ & & \\
\hline Education ( $\geqslant$ high school) & $<$ high school & & & & & $1.89^{* * *}$ & (1.37 to 2.61$)$ \\
\hline $\begin{array}{l}\text { Employment (in labour } \\
\text { force) }\end{array}$ & Not in labour force & & & & & $1.84^{\star \star \star}$ & (1.36 to 2.48$)$ \\
\hline $\begin{array}{l}\text { Household income } \\
(\geqslant \$ 30000)\end{array}$ & $\leqslant \$ 30,000$ & $2.66^{* * *}$ & (1.85 to 3.81$)$ & $1.51^{*}$ & (1.04 to 2.21$)$ & & \\
\hline $\begin{array}{l}\text { Smoking status (non- } \\
\text { smoker) }\end{array}$ & Smoker & & & $2.10^{\star \star *}$ & $(1.46$ to 3.01$)$ & & \\
\hline BMI (not overweight) & Overweight & $1.92^{\star * *}$ & (1.36 to 2.71$)$ & & & & \\
\hline Exercise (exercise) & No exercise & & & & & & \\
\hline $\begin{array}{l}\text { Length of residence } \geqslant 5 \\
\text { years }\end{array}$ & $<5$ years & & & $1.49^{*}$ & (1.04 to 2.14$)$ & & \\
\hline $\begin{array}{l}\text { Condition of dwelling (no } \\
\text { repairs) }\end{array}$ & Needs major repairs & & & $2.36^{* \star *}$ & (1.57 to 3.56$)$ & & \\
\hline Neighbourhood of & Chedoke-Kirkendall & 1.09 & $(0.61$ to 1.95$)$ & 1.10 & $(0.60$ to 2.00$)$ & 0.88 & $(0.62$ to 1.25$)$ \\
\hline \multirow[t]{3}{*}{ residence ('Old City') } & Downtown Core & 1.29 & $(0.74$ to 2.26$)$ & 1.47 & (0.83 to 2.61$)$ & 0.81 & (0.56 to 1.18 ) \\
\hline & Northeast & $2.07^{* *}$ & (1.23 to 3.49$)$ & 1.40 & (0.81 to 2.42$)$ & 0.85 & $(0.59$ to 1.20$)$ \\
\hline & Mountain & 0.82 & $(0.46$ to 1.48$)$ & 1.17 & $(0.64$ to 2.13$)$ & 0.91 & $(0.65$ to 1.29$)$ \\
\hline $\begin{array}{l}\text { Neighbourhood satisfaction } \\
\text { (satisfied) }\end{array}$ & nissatisfied & & & $2.39^{* * *}$ & (1.40 to 4.09 ) & $1.66^{*}$ & (1.05 to 2.64$)$ \\
\hline $\begin{array}{l}\text { Neighbourhood dislike } \\
\text { (none) }\end{array}$ & $\begin{array}{l}\text { Social } \\
\text { Physical }\end{array}$ & & & & & $\begin{array}{l}1.05 \\
1.56^{* *}\end{array}$ & $\begin{array}{l}(0.75 \text { to } 1.46) \\
(1.19 \text { to } 2.05)\end{array}$ \\
\hline Neighbourhood & Social & $1.80^{*}$ & $(1.05$ to 3.16$)$ & & & & \\
\hline improvement (none) & Physical & 0.93 & (0.61 to 1.41$)$ & & & & \\
\hline Neighbourhood like (none) & Social & 0.64 & $(0.36$ to 1.14$)$ & 0.65 & (0.37 to 1.16$)$ & & \\
\hline & Physical & $0.50^{*}$ & $(0.28$ to 0.90$)$ & $0.45^{\star \star \star}$ & $(0.26$ to 0.80$)$ & & \\
\hline
\end{tabular}




\section{Key points}

- Perceptions of neighbourhood social and physical characteristics may be important determinants of individual health

- In a random sample of adults, our results show significant associations between perceptions of neighbourhood characteristics and three self reported health outcomes (chronic conditions, self rated health status, and emotional health)

- In many instances, neighbourhood perceptions were as important as more traditional risk factors such as poverty and obesity

- Perceptions of the physical environment seem more important than those of the social environment

question, however, because of the low number of responses for the second and third mentions, only the first mention is included in the analysis. Finally, respondents were asked to rate their overall neighbourhood satisfaction on a four point scale ranging from very satisfied to very dissatisfied. Although we allowed for more scope in the open ended responses, we followed the method used by Ellaway et $a l^{17}$ of classifying responses obtained for each of three open ended questions into categories that were either "social" (for example, lack of safety, friendliness of neighbours) or "physical" (for example, green space, pollution). Reliability in coding was ensured by dual coding of the responses by more than one researcher. Table $2 \mathrm{~A}$ illustrates the typical responses assigned to each category and table $2 \mathrm{~B}$ shows selected examples of social and physical neighbourhood characteristics. The following section reports results of descriptive analyses and multivariate logistic regressions.

\section{RESULTS}

Significant differences in health status across the four neighbourhoods are apparent, with twice as many respondents in the Downtown and Northeast neighbourhoods reporting fair/poor health as compared with the ChedokeKirkendall and Mountain neighbourhoods (table 3). While little variation in the reporting of chronic conditions exists, a much higher percentage of residents in the Downtown Core and the Northeast neighbourhoods scored above the cut off point $(\geqslant 4)$ on the GHQ-20, indicating a probable case of emotional distress. Almost $50 \%$ of Mountain respondents reported no dislikes about their neighbourhood, much higher

\section{Policy implications}

- Public health policymakers may have to spend more time assessing localised perceptions about neighbourhoods

- More emphasis may need to be given to residents' perceptions of physical environmental factors in the formulation of local public health policies

- Suggests importance of public consultations for informing local level health planning

- The time needed to assess perceived neighbourhood problems or opportunities for improvement may prevent some local authorities from adopting progressive policies than the other three neighbourhoods (table 3). Similarly, the highest percentage of respondents reporting no potential neighbourhood improvements for improving health was also in the Mountain neighbourhood (see table 3).

A particular focus of this work was to differentiate between social and physical aspects of the neighbourhood. For almost all indicators, physical aspects of neighbourhood were mentioned with greater frequency than social aspects (table 3). Social dislikes were reported with the greatest frequency by respondents in the Downtown neighbourhood (35\%). Physical dislikes were reported with the greatest frequency in the Chedoke-Kirkendall (52\%) and Northeast $(52 \%)$ neighbourhoods, both areas with proximate industrial land use. Almost 20\% of Downtown residents report dissatisfaction as compared with less than 5\% of Mountain and Chedoke-Kirkendall respondents. With respect to suggestions for neighbourhood improvements that may affect health and wellbeing, most were physical (table 3), with the highest levels of reporting in the Chedoke-Kirkendall and Northeast neighbourhoods. Although the level of reporting of social improvements was much lower, the highest frequency of reporting was in the Downtown neighbourhood (20\%). For example, "get rid of prostitutes" was a frequent response.

Table 4 gives the results of logistic regression models for each of the three health outcomes. Consistent with past research on self assessed health status, ${ }^{30-32}$ low household income, and being overweight are associated with increased odds of being in poor health (table 4). Three of the neighbourhood variables are significantly related to self assessed health status. Respondents living in the Northeast neighbourhood are twice as likely to report fair/poor health (OR 2.07, 95\% CI 1.23 to 3.49) as compared with people living in the "Old City" area. People who report that they want to improve the social aspects of their neighbourhood have increased odds of reporting fair/poor health (OR 1.80, 95\% CI 1.05 to 3.16) relative to those who report no improvements. In contrast, people who report that they like physical characteristics of their neighbourhood are less likely to rate their health as fair/poor (OR $0.50,95 \%$ CI 0.28 to 0.90 ) as compared with those who report that they like nothing about their neighbourhood.

With respect to emotional health, women, smokers, and those with an annual household income below the LICO have significantly increased odds of scoring above the GHQ-20 cut off point than do men, non-smokers, and those above the LICO. Respondents who have lived in their neighbourhood for less than five years and those living in homes in need of major repairs are more likely to score above the GHQ-20 cut off point than those who have resided in their neighbourhood for more than five years and those living in homes not requiring major repairs. Similarly, people who are dissatisfied with their neighbourhood as a place to live have increased odds of scoring above the cut off point (OR 2.39, 95\% CI 1.40 to 4.09 ) than those who are satisfied, while those who like their neighbourhood's physical aspects have decreased odds (OR $0.45,95 \%$ CI 0.26 to 0.80 ) as compared with those who report no neighbourhood likes.

The model for chronic conditions shows that the odds of reporting one or more chronic conditions increases with age, again consistent with past finding s $^{34}$ (table 4). Low education levels and unemployment are both associated with increased odds of reporting one or more chronic conditions. Respondents who are dissatisfied with their neighbourhood (OR 1.66, 95\% CI 1.05 to 2.64 ) or report that they dislike physical aspects of their neighbourhood (OR 1.56, 95\% CI 1.19 to 2.05) both have increased odds of reporting one or more chronic conditions. This observation may be linked to arguments suggesting that people with physical impairments (that is, long term physical conditions) may rate their 
neighbourhoods as more problematic than less impaired people because of mobility restrictions. ${ }^{18}$

\section{DISCUSSION}

The results indicate that significant differences in health status across the four neighbourhoods are apparent in self assessed health status and emotional distress, but this is not the case for chronic conditions. Neighbourhoods with lower SES reported poorer health and more emotional distress. Perceptions of the physical environment seem more important than those of social concerns in all neighbourhoods. For all three health outcomes, individual risk factors followed expectations, with measures of SES, age, and lifestyle all significantly associating with poor health outcomes. Physical environmental problems were significantly associated with chronic conditions while reporting physical likes were associated with both lower odds of reporting poor self assessed health status and lower odds of scoring above the GHQ cut off point.

Our results show the importance of individual perceptions of neighbourhoods for shaping health. The neighbourhood of residence dummy variable was entered into all three models but was only significant for self assessed health. This suggests that perceptions about the neighbourhoods in which people live are just as important for health as the neighbourhoods themselves.* Much of the research linking neighbourhood perceptions to health has focused on neighbourhood problems. ${ }^{16-18}$ In our analysis, we not only test for the health inhibiting (that is, dissatisfaction, dislikes and suggestions for improvement) aspects of physical and social neighbourhood environments but also the health promoting (that is, likes) aspects. Our results suggested a differentiated relation between health inhibiting and health promoting aspects and each of the three health outcomes. Neighbourhood dissatisfaction and physical dislikes were associated with increased odds of reporting chronic conditions while physical likes were associated with decreased odds of fair/poor health and scoring above the GHQ-20 cut off point. Finally, respondents who stated that the social aspects of their neighbourhood needed improving were more likely to report fair/poor health. Overall, however, physical environmental concerns dominated social ones as determinants of health. In discussing the importance of perception, a few methodological and interpretive problems deserve mention.

Firstly, the findings showed significant differences in both health status and perceptions of social and physical dimensions of neighbourhood among the four study neighbourhoods (table 3 ). It may be the case that social and physical characteristics have differential levels of importance for health in different neighbourhoods. It is possible that physical aspects might be a strong predictor of health in the Northeast Industrial neighbourhood due to its proximity to the steel industry and the comparatively high pollution levels there..$^{35}$ In contrast, social aspects might have a stronger effect in the Downtown Core where there are higher rates of crime, homelessness, drug trafficking, and prostitution. These questions await further research.

Another limitation may be our definition of neighbourhood. While much research has used administrative districts, such as census tracts, ${ }^{11}$ this study sought to define the boundaries of neighbourhoods through spatial clusterings of specific demographic and socioeconomic features with the input of key decision makers in the city. ${ }^{24}$ Had the boundaries

*Objective measures of neighbourhood environments may be important predictors of health, however, ambient air quality data (TSP and $\mathrm{SO}_{2}$ ) based on postal code data were included in supplementary analyses but were not significantly related to the health outcomes. been drawn differently, relations between neighbourhood and health might be different. Furthermore, as Caughy et $a^{14}$ note, specification of neighbourhoods for research purposes does not always match perceptions of neighbourhood boundaries of residents. ${ }^{36} 37$

The use of open ended questions may have introduced some bias in the models with the tendency of some respondents to report always positively or negatively. However, we chose this method for measuring neighbourhood perceptions (in contrast with pre-defined lists of characteristics) as it allows respondents to identify those characteristics most important to them.

Furthermore, we cannot conclude if perceptions of social and physical neighbourhood characteristics reflect the local environment in which people live or individual attributes (for example, state of mind, health status). That is, the relation between perceptions of neighbourhood characteristics and health are not necessarily causal. Ellaway et $a l^{17}$ argue that results like these show that either people in poor health are more negative about their neighbourhoods or people with a pessimistic view are more likely to report both their health and neighbourhoods are poor. In addition, as Diez Roux ${ }^{39}$ notes, health and neighbourhood characteristics, such as physical and social environments, may influence each other. $^{22} 23$

Despite these limitations such findings support the suggestions of Macintyre et $a l^{39}$ that "a more differentiated picture has tended to emerge, in which rather than there being one single, universal 'area effect on health' there appear to be some area effects on some health outcomes, in some population groups, and in some types of areas" (page 128). While it is not possible to identify which specific social and physical attributes of neighbourhoods are health promoting and which are health inhibiting, the research demonstrates the importance of neighbourhood perceptions for health. The dominance of physical concerns over social ones may have resulted from the industrial nature of Hamilton, but this finding highlights the need for further research to identify factors driving perceptions of place as a determinant of health.

\section{ACKNOWLEDGEMENTS}

The authors would like to thank the editors of the Journal of Epidemiology and Community Health and three anonymous reviewers for their extremely helpful comments and suggestions.

\section{Authors' affiliations}

K Wilson, Department of Geography, University of Toronto at Mississauga, Mississauga, Ontario, Canada

K Wilson, S Elliott, M Law, J Eyles, M Jerrett, S Keller-Olaman, McMaster Institute of Environment and Health, McMaster University, Hamilton, Ontario, Canada

S Elliott, J Eyles, M Jerrett, School of Geography and Geology, McMaster University

Funding: the authors gratefully acknowledge the Social Sciences and Humanities Research Council of Canada for funding under its Society, Culture and the Health of Canadians strategic area and other members of the research team. We also recognise the contributions of our community partners (Central West Health Planning Information Unit, De dwa da dehs nye $>$ s Aboriginal Health Centre, Hamilton Community Care Access Centre, Hamilton District Health Council, Hamilton Social and Public Health Services, Social Planning and Research Council of Hamilton).

Conflicts of interest: none declared.

\section{REFERENCES}

1 Cattell V. Poor people, poor places, and poor health: the mediating role of social networks and social capital. Soc Sci Med 2001;52:1501-16. 
2 Boyle PJ, Gattrell AC, Duke-Williams O. Do area-level population change, deprivation and variations in deprivation affect individual-level self-reported limiting long-term illness? Soc Sci Med 2001;53:755-99.

3 Carstairs V, Morris R. Deprivation and mortality: an alternative to social class? Community Med 1989;11:210-19.

4 Davey Smith G, Hart C, Watt G, et al. Individual social class, area-based deprivation, cardiovascular disease risk factors, and mortality: the Renfrew and Paisley study. J Epidemiol Community Health 1998;52:399-405.

5 Veugelers PJ, Hornibrook S. Small area comparisons of health: applications for policy makers and challenges for researchers. Chronic Dis Can 2002;23:100-10.

6 Veugelers PJ, Yip AM, Kephart G. Proximate and contextual socioeconomic determinants of mortality: Multilevel approaches in a setting with universal health care coverage. Am J Epidemiol 2001;154:725-32.

7 Anderson RT, Sorlie P, Backlund E, et al. Mortality effects of community socioeconomic status. Epidemiology 1997;8:42-7.

8 Diez Roux AV. Neighbourhood environments and coronary heart disease: a multilevel analysis. Am J Epidemiol 1997; 146:48-63.

9 Malmstrom M, Sundquist J, Johansson SE. Neighborhood environment and self-reported health status: a multilevel analysis. Am J Public Health 1999:89:1181-6.

10 Subramanian SV, Kawachi I, Kennedy BP. Does the state you live in make a difference? Multilevel analysis of self-rated health in the US. Soc Sci Med 2001;53:9-19.

11 Pickett KE, Pearl M. Multilevel analyses of neighbourhood socioeconomic context and health outcomes: a critical review. J Epidemiol Community Health 2000;55: $111-22$

12 Haan N, Kaplan GA, Camacho T. Poverty and health: prospective evidence from the Alameda County study. Am J Epidemiol 1987;125:989-98.

13 Macintyre S, Maciver S, Sooman A. Area, class and health: Should we be focusing on places or people? Journal of Social Policy 1993;22:213-34.

14 Caughy $M, O^{\prime}$ Campo $P$, Muntaner $C$. When being alone might be better: neighbourhood poverty, social capital, and child mental health. Soc Sci Med 2003;57:227-37

15 Russ-Eft D. Identifying components comprising neighborhood quality of life. Social Indicators Research 1979;6:349-72.

16 Balfour JL, Kaplan GA. Neighborhood environment and loss of physical function in older adults: evidence from the Alameda County study. Am J Epidemiol 2002; 155:507-15.

17 Ellaway A, Macintyre S, Kearns A. Perceptions of place and health in socially contrasting neighbourhoods. Urban Stud 2001;38:2299-316.

18 Steptoe A, Feldman PJ. Neighborhood problems as sources of chronic stress: development of a measure of neighborhood problems, and associations with socioeconomic status and health. Ann Behav Med $2001 ; 23: 177-85$.

19 Campbell J. Ambient stressors. Environ Behav 1983;15:355-80.

20 Dalgard OS, Tambs K. Urban environment and mental health: A longitudinal study. Br J Psychiatry 1997;171:530-6.
21 Latkin CA, Curry AD. Stressful neighborhoods and depression: a prospective study of the impact of neighbourhood disorder. J Health Soc Behav 2003;44:34-44.

22 Cattell V, Herring R. Social capital, generations and health in East London. In: Swann C, Morgan A, eds. Social capital for health: insights from qualitative research. London: Health Development Agency, London, 2002:61-85.

23 Skjaeveland O, Garling T. Effects of interactional space on neighbouring. J Environ Psychol 1997; 17:181-98

24 Luginaah I, Jerrett $M$, Elliott $S$, et al. Health profiles of Hamilton: spatial characterization of neighbourhoods for health investigations. Geo Journal 2001;53:135-47.

25 Goldberg DP. The detection of psychiatric illness by questionnaire. London: Oxford University Press, 1972

26 McDowell I, Newell C. Measuring health: a guide to rating scales and questionnaires. London: Oxford University Press, 1987.

27 Dunn J. Housing and inequalities in health: a study of socioeconomic dimensions of housing and self reported health from a survey of Vancouver residents. J Epidemiol Community Health 2002;56:671-81.

28 Yang MS, Shih $\mathrm{CH}$, Kawachi I. Development and validation of an instrument to measure perceived neighbourhood quality in Taiwan. J Epidemiol Community Health 2002;56:492-6.

29 Ford BL. An overview of hot-deck procedures. In: Madow WG, Olkin I, Rubin DB, eds. Incomplete data in sample surveys. New York: New York Academic Press, 1983:185-207.

30 Damush TM, Stump TE, Clark DO. Body-mass index and 4-year change in health-related quality of life. J Aging Health 2002;14:195-210.

31 Wilson $\mathrm{K}$, Jerrett $\mathrm{M}$, Eyles J. Testing relationships among determinants of health, health policy, and self-assessed health status in Quebec. Int $J$ Health Serv 2001;31:67-89.

32 Birch S, Jerrett $M$, Eyles J. Heterogeneity in the determinants of health and illness: the example of socioeconomic status and smoking. Soc Sci Med 2000:51:307-17

33 Moore EG, Rosenberg MW, Fitzgibbon SH. Activity limitation and chronic conditions in Canada's elderly, 1986-2011. Disabil Rehabil 1999;21:196-210.

34 Rosenberg M, Wilson K. Gender, poverty and location: how much difference do they make in the geography of health inequalities? Soc Sci Med 2000;51:275-87.

35 Jerrett $M$, Kanaroglu $P$, Eyles J, et al. A GIS-environmental justice analysis of particulate air pollution in Hamilton, Canada. Environ Plan A 2000;33:955-73

$36 \mathbf{O}^{\prime}$ Campo P. Advancing theory and methods for multilevel models of residential neighbourhoods and health. Am J Epidemiol 2003;157:9-13.

37 Diez Roux AV. Investigating neighborhood and area effects on health. Am J Public Health 2001;91:1783-9.

38 Diez Roux AV. Places, people, and health. Am J Epidemio 2002;155:516-19.

39 Macintrye S, Ellaway A, Cummins S. Place effects on health: how can we conceptualise, operationalise and measure them? Soc Sci Med 2002:55:125-39.

\section{APHORISM OF THE MONTH}

\section{Doing health: reclaiming the " $\mathrm{H}$ " word}

$M$

ark Twain famously said that he had been writing prose for 20 years before he knew

that that was what he was doing. It is the same with health. Health is created and

lost in everyday life by individuals, families, and organisations in the settings where people live, love, work, and play. The reluctance of many people from different sectors to admit that they are involved in health work puzzled me for many years. One day the penny dropped. The medicalisation of health has led to a linguistic impasse in which health care workers claim to be doing health while predominantly concerning themselves with treating disease, while those actually doing health are reluctant to admit that they are doing so for fear that they will be put under the direction of clinical workers. We need to reclaim the " $\mathrm{H}^{\text {" }}$ word to make it legitimate for non-medical and nursing people to be seen to be in the lead on many health protecting and creating activities, while at the same time exploring the opportunities for health care workers to also contribute to the broad sweep of public health as well as their specific contributions to disease management. 